\title{
Combined effect of recombinant human adenovirus p53 and curcumin in the treatment of liver cancer
}

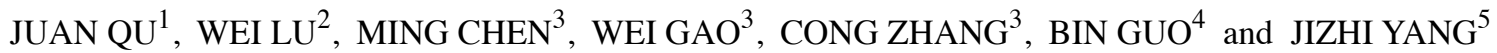 \\ ${ }^{1}$ Department of Gastroenterology, Tianjin Nankai Hospital, Tianjin 300100; ${ }^{2}$ Department of Gastroenterology, \\ Tianjin Cancer Hospital, Tianjin 300060; ${ }^{3}$ Department of Hepatopathy and Hepatic Oncology, Tianjin Nankai Hospital, \\ Tianjin 300100; ${ }^{4}$ College of Acu-moxibustion and Massage, Hunan University of Chinese \\ Medicine, Changsha, Hunan 410208; ${ }^{5}$ Department of Traditional Chinese Medicine, \\ Chentangzhuang Street Health Service Center, Tianjin 300222, P.R. China
}

Received February 10, 2019; Accepted January 17, 2020

DOI: 10.3892/etm.2020.9145

\begin{abstract}
The development of an effective therapeutic intervention for liver cancer is a worldwide challenge that remains to be adequately addressed. Of note, TP53, which encodes the p53 protein, is an important tumor suppressor gene, $61 \%$ of TP53 is functionally inactivated in liver cancer. Recombinant human adenovirus p53 (rAd-p53) is the first commercial product that has been used for gene therapy. In the present study, the combined mechanistic effects of rAd-p53 and curcumin, a naturally occurring compound with previously reported anti-inflammatory, antioxidant and anti-cancer properties, were assessed in liver cancer cells, using HepG2 cells as the model cell line. The administration of either curcumin or rAd-p53 promoted apoptosis, suppressed epithelial-mesenchymal transition (EMT) and blocked G2/M phase progression in HepG2 cells, which were potentiated further when both agents were applied together. Combined rAd-p53 and curcumin treatment resulted in higher p53 $(\mathrm{P}<0.01)$ and $\mathrm{p} 21(\mathrm{P}<0.01)$ expression compared with rAd-p53 or curcumin were added alone, suggesting an additive effect on TP53 expression. Additionally, curcumin and rAd-p53 were demonstrated to regulate the activation of mitogen-activated protein kinases (MAPKs) ERK1/2, p38 MAPK and JNK. These results indicated that the combination of rAd-p53 with curcumin synergistically potentiates apoptosis and inhibit EMT compared with either rAd-p53 or curcumin treatment alone via the regulation of TP53 regulation. Mechanistically, this effect on TP53 expression may involve the ERK1/2, p38 MAPK and JNK signaling pathways. The current study
\end{abstract}

Correspondence to: Mr. Jizhi Yang, Department of Traditional Chinese Medicine, Chentangzhuang Street Health Service Center, 29 Little Haiti Maoming Road, Hexi, Tianjin 300222, P.R. China E-mail: 496443161@qq.com

Key words: hepatocellular carcinoma, rAd-p53, curcumin, TP53, mitogen activated protein kinase provides new insights that can potentially advance the development of therapeutic strategies for liver cancer treatment.

\section{Introduction}

Liver cancer currently ranks as the third most common cause of mortality associated cancer worldwide, with $>600,000$ deaths reported annually $(1,2)$. Liver cancer commonly occurs in patients with a history of chronic liver conditions, including hepatitis B and $\mathrm{C}$ viral infections, alcoholic or non-alcoholic liver disease, fatty liver disease and chronic liver disease that is caused by aflatoxin poisoning (3), in a vicious cycle of liver injury, regeneration and inflammation (1). Since effective clinical diagnosis and treatment of liver cancer is typically hindered by high rates of recurrence and metastasis $(2,3)$, it is of importance to develop innovative therapeutic strategies for the diagnosis and treatment of liver cancer.

TP53 is an important human tumor suppressor gene that is present on chromosome 17p13.1 (4), which contains 11 exons that encodes 393 amino acid residues and is one of the most commonly mutated genes in African-Asian populations (5). The p53 protein is a transcriptional product of TP53 that is associated with the inhibition of tumor cell division, induction of tumor cell apoptosis and the repair of DNA damage (6). In different types of tumors, mutations in the TP53 gene directly result the inactivation of p53 protein $(4,6,7)$. TP53 mutations have been identified in malignant tumors of the lung, gastric, liver, breast and bladder, where p53 was found to be inactivated or dysfunctional $(8,9)$. Therefore, it would be of great significance to utilize the tumor suppressive properties of functional p53 for use in cancer treatment.

Recombinant human adenovirus p53 (rAd-p53; also known as Gendicine ${ }^{\circledR}$ ) is a replication-incompetent recombinanthuman serotype 5 adenovirus, where the virulent $\mathrm{E} 1$ region has been replaced by the human wild-type p53 expression cassette (10). It is the first commercially available product used for gene therapy and has been applied in the treatment of a number of cancer types, including head and neck cancer, epithelial ovarian carcinoma and liver cancer $(11,12)$. rAd-p53 has been previously reported to enhance the sensitivity of gastric cancer cells to chemotherapy by regulating the expression of proteins 
that are associated with apoptosis (13). Clinical research has also demonstrated that rAd-p53-based transarterial chemoembolization is an effective and safe strategy for the treatment of unresectable liver cancer (14). However, treatment with rAd-p53 alone has proven to be insufficient for improving the survival of patients with cancer (15-17).

In some cancer malignancies, including in liver cancer, the aberrant tumor microenvironment may lead to subsequent mutation of the TP53 gene. In liver cancer cells, DNA damage and TP53 mutation have been previously associated with certain stimuli, including chronic inflammation and intracellular oxygen or nitrogen metabolites (18). Therefore, the introduction of exogenous wild-type TP53 in combination with anti-inflammatory and anti-oxidant agents that interfere with the tumor microenvironment but do not effect normal healthy cells, may produce improved therapeutic outcomes. Curcumin, a naturally occurring active compound extracted from the rhizome and root of the Curcuma longa plant, possesses antioxidant and anti-inflammatory properties (19) and has been demonstrated to be safe under clinical settings (20). As a result, curcumin has been considered as a promising therapeutic and preventative agent against liver cancer (21-23). However, the use of curcumin remains limited by its low bioavailability (21). In the present study, the treatment strategy of rAd-p53 combined with curcumin was investigated on HepG2 cells. Cell proliferation, apoptosis, expression of proteins targeted by the TP53 gene and the activation of mitogen-activated protein kinase (MAPK) signaling pathways were evaluated following treatment with rAd-p53 or curcumin individually and in combination. The results from the present study may assist in the development of therapeutic strategies involving rAd-p53 for use in the treatment of liver cancer.

\section{Materials and methods}

Cell culture and treatment. The human hepatocyte cell line HHL-5 and liver cancer cell lines HepG2, Hep3B and Huh-7 were supplied by the Type Culture Collection of the Chinese Academy of Sciences. Authentication of the cell lines was performed by STR profiling. Cells were maintained in RPMI 1640 medium (Hyclone; GE Healthcare Life Sciences) supplemented with $10 \%$ FBS (Gibco; Thermo Fisher Scientific, Inc.) at $37^{\circ} \mathrm{C}$ under $5 \% \mathrm{CO}_{2}$. All cells were subjected to treatment once $\sim 90 \%$ confluence was achieved. Curcumin (Sigma-Aldrich; Merck KGaA) was dissolved in DMSO and administered at $37^{\circ} \mathrm{C}$ to the cells at $10 \mu \mathrm{M}$. rAd-p53 (Sibiono GeneTech Co. Ltd.) was stored at $-20^{\circ} \mathrm{C}$ at a density of $1 \times 10^{12}$ virus particles $/ \mathrm{ml}$. Prior to each experiment, cells were infected at $37^{\circ} \mathrm{C}$ with rAd-p53 particles at a multiplicity of infection of 100 using a previously reported protocol (10). HHL-5 cells either remained untreated (control/Con) or were treated with curcumin (Cur) to evaluate the toxicity of curcumin on normal hepatocytes. HepG2, Hep3B and Huh-7 cells were divided into four groups in accordance with the treatments they received: Con (control), rAd-p53 alone, Cur alone and Cur + rAd-p53.

Cell counting Kit-8 (CCK-8) assay. HHL-5 (untreated or treated with curcumin), HepG2, Hep3B and Huh-7 cells (either treated with/without rAD-p3 and/or curcumin) were seeded at the density of $3 \times 10^{3}$ cells/well into 96 -well plates and subsequently cultured for 24, 48 and $72 \mathrm{~h}$. Subsequently, a total of $10 \mu \mathrm{l} \mathrm{CCK}-8$ solution (Bioswamp; Wuhan Beinglay Biotech Co., Ltd.) was added to each well, followed by further incubation at $37^{\circ} \mathrm{C}$ for 4 h. Subsequently, a SpectraMax ${ }^{\circledR} 190$ Microplate Reader (Molecular Devices, LLC) was used to measure the absorbance in each well at $450 \mathrm{~nm}$.

Following treatment with or without rAD-p53 and/or curcumin for $72 \mathrm{~h}$, HepG2 cells were incubated in RPMI-1640 medium containing 10\% FBS without rAD-p53 and/or curcumin at $37^{\circ} \mathrm{C}$ for 0,24 and $48 \mathrm{~h}$. Cell viability was detected using a CCK-8 assay as aforementioned. All experiments were performed in triplicate.

Wound healing assay. HepG2 cells were first seeded into six-well plates at $1 \times 10^{6}$ cells/well and incubated in DMEM (Hyclone; GE Healthcare Life Sciences) supplemented with $10 \%$ FBS. When $\sim 90 \%$ confluence was reached, the cell monolayers were wounded by scratching with a sterile 200 $\mu l$ plastic pipette tip, following which the cells were cultured in serum-free medium (DMEM) at $37^{\circ} \mathrm{C}$ under $5 \% \mathrm{CO}_{2}$ for 24,48 or $72 \mathrm{~h}$. The wounds were imaged using an inverted fluorescence microscope equipped with a camera (Nikon Corporation).

Flow cytometry analysis. Flow cytometry was performed to evaluate the apoptosis and cell cycle progression in HepG2 cells. For apoptosis, the Annexin V/PI staining method was performed according to the manufacturer's protocol (Bioswamp; Wuhan Beinglay Biotech Co., Ltd.). Following treatment, the cells $\left(2 \times 10^{6}\right.$ cells $\left./ \mathrm{ml}\right)$ were digested using ethylenediaminetetraacetic acid-trypsin (Bioswamp; Wuhan Beinglay Biological Technology Co., Ltd.), washed with pre-cooled PBS and resuspended in binding buffer. Annexin V-fluorescein isothiocyanate and PI (10 $\mu \mathrm{l}$ each) were subsequently added to the cells, following which they were incubated for $30 \mathrm{~min}$ at $4^{\circ} \mathrm{C}$ in the dark and subjected to the flow cytometry (Beckman Corporation) and the data were analyzed using CXP Analysis 2.0 software (Beckman Corporation).

For analyzing cell cycle progression, the harvested cells $\left(2 \times 10^{7}\right.$ cells $\left./ \mathrm{ml}\right)$ were washed twice with pre-cooled PBS and incubated with a mixture of $100 \mu 11 \mathrm{mg} / \mathrm{ml}$ RNase A (Takara Biotechnology Co., Ltd.) and $400 \mu 150 \mu \mathrm{g} / \mathrm{ml}$ PI in the dark at room temperature for $10 \mathrm{~min}$. The treated cells were then subjected to flow cytometry (Beckman Coulter, Inc.) and analyzed using ModFit LT 2.0 (Verity Software House).

Western blot analysis. The expression of proteins associated with cell cycle progression, apoptosis, TP53 targets p53 and p21, MAPK signaling and epithelial-mesenchymal transition (EMT) was evaluated using western blot analysis. Total protein content in HepG2 cells was extracted using a radioimmunoprecipitation assay lysis buffer (Bioswamp; Wuhan Beinglay Biotech Co., Ltd.) containing protease and phosphatase inhibitors. Proteins were quantified using the BCA kit (Bioswamp; Wuhan Beinglay Biotech Co., Ltd.). A total of $10 \mu \mathrm{g}$ proteins were separated using SDS-PAGE (12\%) and transferred onto PVDF (EMD Millipore). The membranes were then blocked with $5 \%$ skimmed milk for $2 \mathrm{~h}$ at room temperature and incubated with primary antibodies overnight at $4^{\circ} \mathrm{C}$. After washing, the membranes were incubated with secondary 
Table I. Antibodies used in this study.

\begin{tabular}{|c|c|c|c|c|c|}
\hline Antibody & Species & Company & Product code & Dilution & Protein size $(\mathrm{kDa})$ \\
\hline \multicolumn{6}{|l|}{ Primary antibodies } \\
\hline p53 & rabbit & Abcam & ab131442 & $1: 1,000$ & 53 \\
\hline $\mathrm{p} 21$ & rabbit & Abcam & ab109199 & $1: 1,000$ & 18 \\
\hline p-ERK1/2 & rabbit & Abcam & $a b 223500$ & $1: 400$ & $42-44$ \\
\hline ERK1/2 & rabbit & Abcam & ab17942 & $1: 1,000$ & $42-44$ \\
\hline p-p38MAPK & rabbit & Abcam & $\mathrm{ab} 47363$ & $1: 1,000$ & 41 \\
\hline p38MAPK & rabbit & Abcam & ab27986 & $1: 1,000$ & 41 \\
\hline $\mathrm{p}-\mathrm{JNK}$ & rabbit & Abcam & ab124956 & $1: 5,000$ & $46-54$ \\
\hline JNK & rabbit & Abcam & ab179461 & $1: 1,000$ & $46-54$ \\
\hline Caspase3 & rabbit & Abcam & ab90437 & $1: 1,000$ & 32 \\
\hline Caspase8 & rabbit & Abcam & ab227430 & $1: 2,000$ & 55 \\
\hline Caspase9 & rabbit & Abcam & ab2013 & $1: 2,000$ & 46 \\
\hline Bax & rabbit & Abcam & ab53154 & $1: 1,000$ & 21 \\
\hline Bcl-2 & rabbit & Abcam & ab196495 & $1: 2,000$ & 26 \\
\hline Cyclin A & rabbit & Abcam & ab137769 & $1: 2,000$ & 49 \\
\hline Cyclin E & rabbit & Abcam & ab33911 & $1: 2,000$ & 50 \\
\hline $\mathrm{N}$-cadherin & rabbit & Abcam & ab18203 & $1: 1,000$ & 100 \\
\hline Snail & rabbit & Abcam & ab216347 & $1: 1,000$ & 29 \\
\hline Twist & rabbit & Abcam & ab49254 & $1: 400$ & 21 \\
\hline GAPDH & rabbit & Proteintech & 10494-1-AP & $1: 5,000$ & 36 \\
\hline \multicolumn{6}{|l|}{ Secondary antibody } \\
\hline Goat anti-rabbit IgG & goat & Bioswamp & SAB43658 & $1: 20,000$ & $\mathrm{~N} / \mathrm{A}$ \\
\hline
\end{tabular}

antibody for $1 \mathrm{~h}$ at room temperature. Immunoreactivity was visualized by colorimetric reaction using ECL substrate buffer (EMD Millipore). The membranes were then detected by an automatic chemiluminescence analyzer (Tanon-5200; Tanon Science and Technology Co., Ltd.) and the band gray values were read using TANON GIS 4.2 software (Tanon Science and Technology Co., Ltd.). All experiments were performed in triplicate. Detailed information of all antibodies used in the present study are presented in Table I.

Reverse transcription-quantitative PCR (RT-qPCR). p53 and p21 mRNA expression in HepG2 cells was measured using RT-qPCR. Total RNA was extracted using TRIzol ${ }^{\circledR}$ (Ambion; Thermo Fisher Scientific, Inc.) according to manufacturer's protocol, and reverse-transcribed into first-strand cDNA using the M-MLV kit (Takara Biotechnology Co., Ltd.) according to manufacturer's protocol. The temperature protocol were as follows: $42^{\circ} \mathrm{C}$ for $1 \mathrm{~h} ; 70^{\circ} \mathrm{C}$ for $15 \mathrm{~min}$ and hold at $16^{\circ} \mathrm{C}$. The cDNA was subsequently used for qPCR using the $\mathrm{SYBR}^{\circledR}$ Green PCR kit (KAPA Biosystems; Roche diagnostics) according to manufacturer's protocols. The following thermocycling conditions were used for the PCR: $95^{\circ} \mathrm{C}$ for $3 \mathrm{~min}$; 39 cycles of denaturation at $95^{\circ} \mathrm{C}$ for $5 \mathrm{sec}$, annealing at $56^{\circ} \mathrm{C}$ for $10 \mathrm{sec}$ and extension at $72^{\circ} \mathrm{C}$ for $25 \mathrm{sec}$ and final extension at $65^{\circ} \mathrm{C}$ for $5 \mathrm{sec}$ and $95^{\circ} \mathrm{C}$ for $50 \mathrm{sec}$. The primer sequences used are as follows: p53 forward, 5'-ATGTTTGTGCCTG CCT-3' and reverse, 5'-CAGTGGTTTCTTCTTTGG-3'; p21 forward, 5'-CGTGAGCGATGGAACTT-3' and reverse, 5'-GCAGAGCAGGTGAGGTG-3' and GAPDH forward,
5'-CCACTCCTCCACCTTTG-3' and reverse, 5'-CACCAC CCTGTTGCTGT-3'. The data were obtained using QuantStudio $^{\mathrm{TM}} 6$ Flex Real-Time PCR System (Applied Biosystems; Thermo Fisher Scientific, Inc.) and analyzed with the $2^{-\Delta \Delta \mathrm{Cq}}$ method (24). The expression of all mRNA was normalized to that of GAPDH. All experiments were performed in triplicate.

Statistical analysis. The data are presented as the mean \pm standard deviation and analyzed using SPSS 19 (IBM Corp.). Differences between $\geq 2$ groups were analyzed using one-way ANOVA followed by a least significant difference whereas those between two groups were analyzed using an unpaired t-test. $\mathrm{P}<0.05$ was considered to indicate a statistically significant difference.

\section{Results}

Cytotoxicity effect of rAd-p53 and/or curcumin on HepG2, Hep3B and Huh-7 cells. The extent of curcumin cytotoxicity was measured in HHL-5 cells. Following $72 \mathrm{~h}$ curcumin treatment $(10 \mu \mathrm{M})$, cell viability was $\sim 70 \%$ of that in control cells (Fig. 1A). rAd-p53 and curcumin treatments alone reduced the cell viability of HepG2, Hep3B and Huh-7 cells, whilst the combined administration of rAd-p53 and curcumin produced additive inhibitory effects compared with Cur, in a time-dependent manner (Fig. 1B-D). Since HepG2 cells appeared to exhibit the highest sensitivity to curcumin and/or rAd-p53 among the liver cancer cell lines (Fig. 1D), it was selected for subsequent 

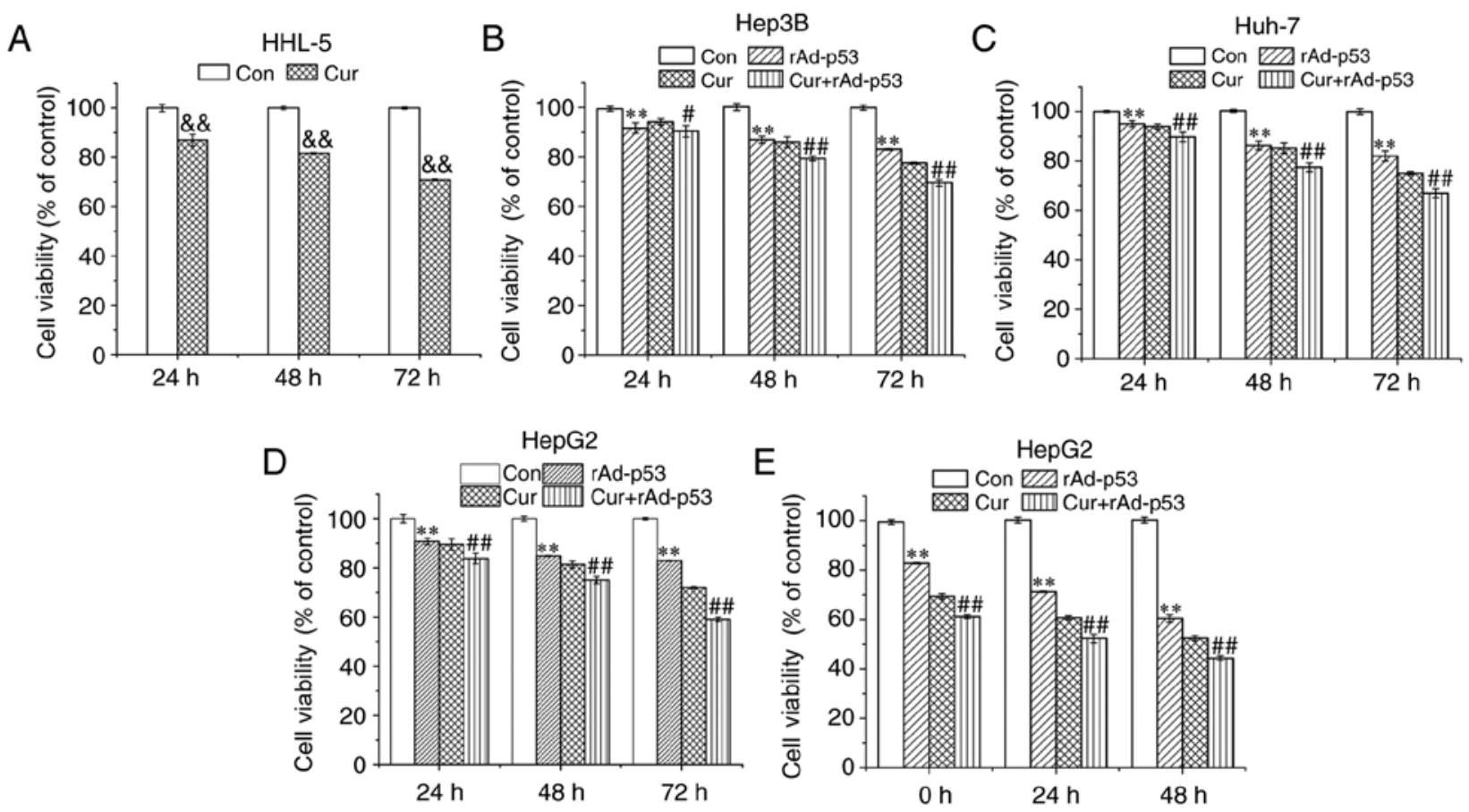

Figure 1. Effect of rAd-p53 and/or curcumin treatment on the viability of hepatocytes and liver cancer cells. Cell Counting Kit-8 analysis of the effect of rAd-p53 and/or curcumin on (A) HHL-5, (B) Hep3B, (C) Huh-7 and (D) HepG2 cells. (E) HepG2 cell viability after the discontinuation of rAD-p53 and/or curcumin. Data are represented as mean \pm standard deviation $(\mathrm{n}=3)$. ${ }^{\&}{ }^{\&} \mathrm{P}<0.01$ vs. Con, ${ }^{* *} \mathrm{P}<0.01$ vs. Con, ${ }^{\#} \mathrm{P}<0.05$ vs. Cur and ${ }^{\# \#} \mathrm{P}<0.01$ vs. Cur. Cur, curcumin; rAd-p53, recombinant human adenovirus-p53; Con, control.

experiments. HepG2 cell viability continued to decrease up to $48 \mathrm{~h}$ after rAD-p53 and/or curcumin was removed (Fig. 1E). These results demonstrated that the combined administration of curcumin and rAd-p53 synergistically reduced HepG2, Hep3B and Huh-7 cell viability.

Combined effect of rAd-p53 and curcumin treatment on HepG2 EMT. The wound healing ability of HepG2 cells treated with either rAd-p53 or curcumin appeared to be inferior compared with that observed for non-treated cells; with the combined treatment of the two agents potentiating this inhibition further in a time-dependent manner (Fig. 2A). The expression of proteins associated with EMT were then evaluated using western blot analysis. Compared with control cells, cells treated with either rAd-p53 or Cur exhibited reduced $\mathrm{N}$-cadherin, snail and twist expression, which was reduced further following combined rAd-p53 and curcumin treatment (Fig. 2B). These observations indicated that the combined administration of curcumin and rAd-p53 additively suppressed EMT in HepG2 cells in a time dependent manner.

Combined effect of rAd-p53 and curcumin administration on Hep 62 apoptosis and intracellular protein expression. The apoptosis of HepG2 cells following a number of treatments is presented in Fig. 3A. The percentage of apoptotic cells in the control group was revealed to be $\sim 2.19 \%$, which were increased to 12.76 and $15.47 \%$ following the individual treatment of either rAd-p53 or Cur alone after $24 \mathrm{~h}$, respectively (Fig. 3A). The combined administration of rAd-p53 and curcumin resulted in a further increase in the percentage of apoptotic cells to $20.29 \%$. After $72 \mathrm{~h}$, whilst the percentage of apoptotic cells in the control group increased slightly (5.85\%), those in the treatment groups were more prominent. A total of $45.61 \%$ of apoptotic cells were observed in the Cur + rAd-p53 group (Fig. 3A).

The expression of proteins associated with apoptosis in HepG2 cells was subsequently evaluated using western blot analysis. Compared with control cells, cells treated with rAd-p53 alone demonstrated significantly higher expression of pro-apoptotic proteins Bax and caspases 3, 8 and 9 , which were potentiated further in cells treated with rAd-p53 and curcumin together (Fig. 4). Following the same rAd-p53 and/or Cur treatment regimens, the expression of the anti-apoptotic protein Bcl-2 exhibited the opposite trend compared with that of the pro-apoptotic proteins (Fig. 4). These results were supported by those obtained from the Annexin V/PI assay. The results collectively indicated that the combined administration of curcumin and rAd-p53 enhanced HepG2 apoptosis.

Combined effect of rAd-p53 and curcumin on HepG2 cell cycle progression and the expression of associated proteins. Treatment with either Cur or rAd-p53 reduced the proportion of cells in the $G_{1} / S$ phase whilst increasing those in the $G 2 / M$ phase compared with the control HepG2 cells. This effect was potentiated further in cells treated with rAd-p53 and curcumin combined (Fig. 3B). No notable differences were observed in the proportion of cells in $\mathrm{S}$ phase between all four treatment groups (Fig. 3B). Supporting this observation, the expression of Cyclins $\mathrm{A}$ and $\mathrm{E}$, which are proteins associated with cell cycle progression, were significantly increased by either rAd-p53 (Fig. 4). This increase was potentiated further following the combined administration of rAd-p53 and curcumin (Fig. 4). These results indicated that the combined administration of 

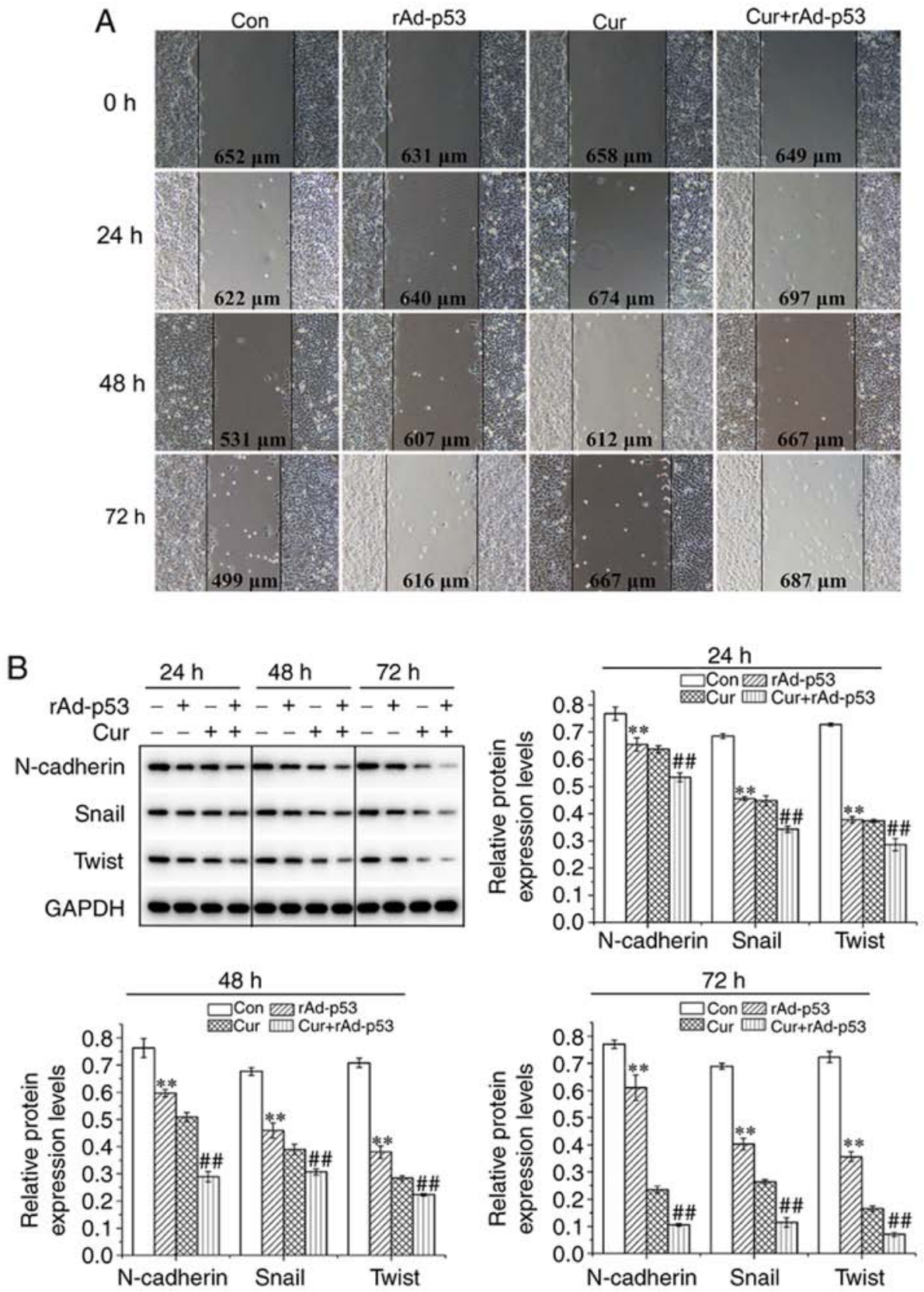

Figure 2. rAd-p53 and/or curcumin synergistically reduces epithelial-mesenchymal transition. (A) The effect of rAd-p53 and/or curcumin on HepG2 cell wound closure following 24, 48 and $72 \mathrm{~h}$ rAd-p53 and/or curcumin treatment. Magnification, x100. (B) Expression of N-cadherin, Snail and Twist in HepG2 cells following 24,48 and $72 \mathrm{~h}$ rAd-p53 and/or curcumin treatment. Data are represented as the mean \pm standard deviation $(\mathrm{n}=3) .{ }^{* *} \mathrm{P}<0.01 \mathrm{vs}$. Con, ${ }^{\# \#} \mathrm{P}<0.01$ vs. Cur. Cur, curcumin; rAd-p53, recombinant human adenovirus-p53; Con, control.

curcumin and rAd-p53 induced a stronger effect compared with Cur treatment alone in altering cell cycle progression.

Combined effect of rAd-p53 and curcumin on the expression of $p 53, p 21$ and MAPKs. In all time points tested, the administration of rAd-p53 alone significantly upregulated p53 and p21 expression in HepG2 cells, which was potentiated further by combined rAd-p53 and curcumin treatment (Fig. 4). Similar trends were observed for the phosphorylation levels of p38 MAPK (p-p38 MAPK) and c-Jun N-terminal kinase (p-JNK), whereas that of extracellular signal-regulated kinases (p-ERK1/2) exhibited the opposite trend (Fig. 5). These results demonstrated that the combined administration of rAd-p53 and curcumin exerted additive regulatory effects on associated signaling pathways compared with Cur treatment alone.

\section{Discussion}

TP53 is an important tumor suppressor gene in the human body, the expression of which is reduced in cancer cells (21). TP53 is found to be functionally inactivated in $50 \%$ of all human cancer cases and $61 \%$ of all liver cancer human cases $(25,26)$, and the downregulation of $\mathrm{p} 53$ protein expression promotes the development of liver cancer (27). Consequently, TP53 is a candidate gene for gene-targeted therapy in human malignancies (28). rAd-p53 is the first commercially available product for gene therapy that has been applied in the treatment of 
A

$24 \mathrm{~h}$

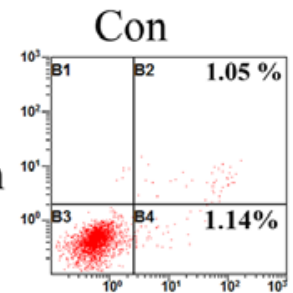

$48 \mathrm{~h}$

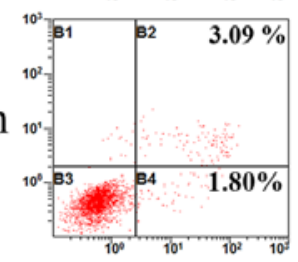

$72 \mathrm{~h}$

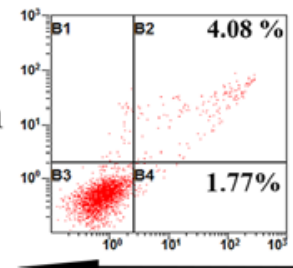

rAd-p53
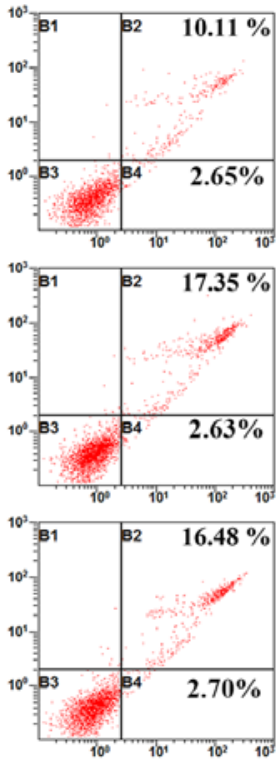

Cur
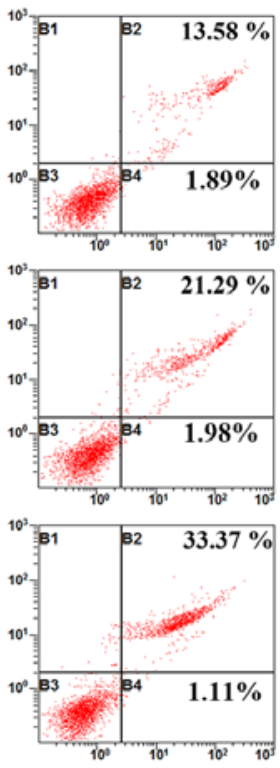

Cur+rAd-p53
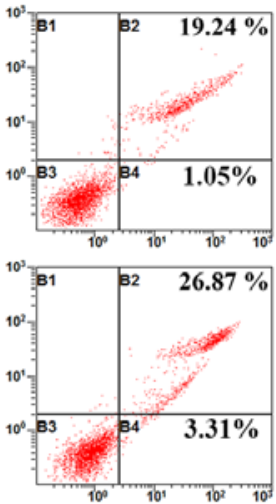

PI

Annexin V-FITC

B
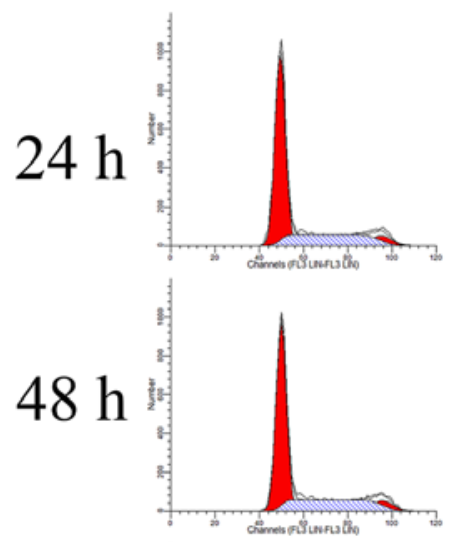

$72 \mathrm{~h}$

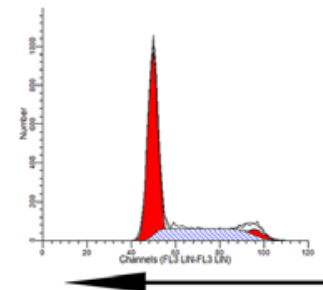

rAd-p53
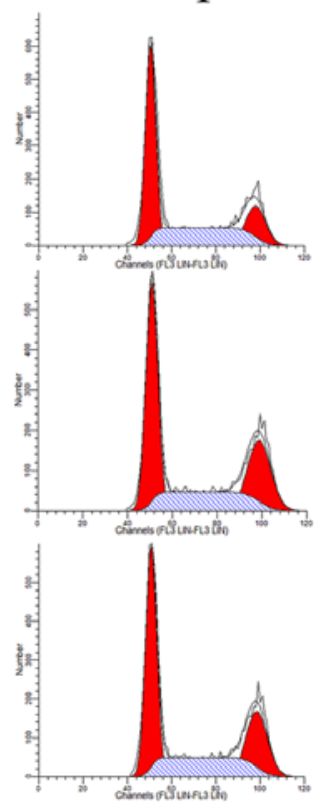

Cur
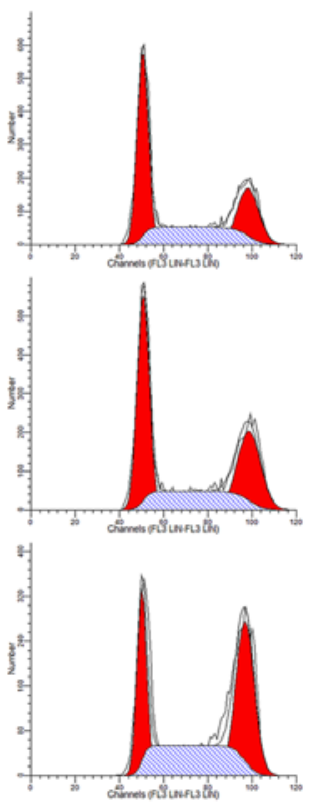

Cur+rAd-p53
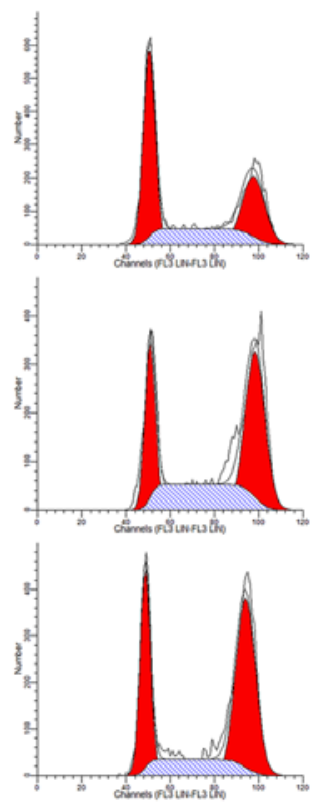

\section{Channels}

Figure 3. rAd-p53 and/or curcumin synergistically potentiates apoptosis and inhibit cell cycle progression. (A) Measurement of HepG2 cell apoptosis following rAd-p53 and/or curcumin treatment by flow cytometry. (B) Measurement of HepG2 cell cycle progression following rAd-p53 and/or curcumin treatment by flow cytometry. Cur, curcumin; rAd-p53, recombinant human adenovirus-p53; Con, control.

head and neck cancer, epithelial ovarian carcinoma and liver cancer $(11,12)$. In most cases, liver cancer occurs and develops as a result of inflammation and oxidative stress $(18,21)$. In the present study, the therapeutic effects of combining rAd-p53 with curcumin, which is a compound exhibiting excellent anti-inflammatory and antioxidant properties $(20,21)$, was explored in liver cancer, using HepG2 cells as the model cell line. This combinatorial administration was demonstrated to synergistically promote apoptosis, inhibit $\mathrm{G}_{2} / \mathrm{M}$ phase progression and suppress EMT in HepG2 cells.
rAd-p53 is a relatively effective and safe means of treatment forliver cancer $(29,30)$ and is usually applied in combination with other therapies, including transarterial chemoembolization (14) and 5-fluorouracil administration (31). Previous clinical studies have revealed that $\mathrm{rAd}-\mathrm{p} 53$ injection may improve the survival rate of patients with liver cancer $(14,32,33)$. Additionally, the combination of rAd-p53 with N-Myc downstream-regulated gene 2 increased p53-mediated apoptosis of HepG2 and Huh7 cells in a previous study (34). In the present study, rAd-p53 was revealed to upregulate the expression of p53 in HepG2 


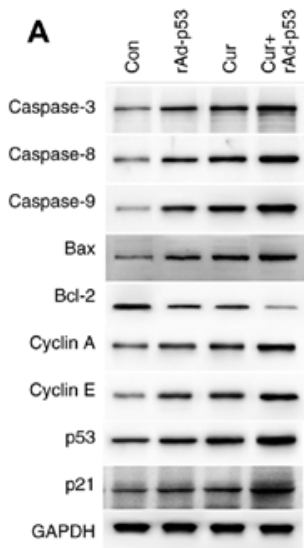

$24 \mathrm{~h}$
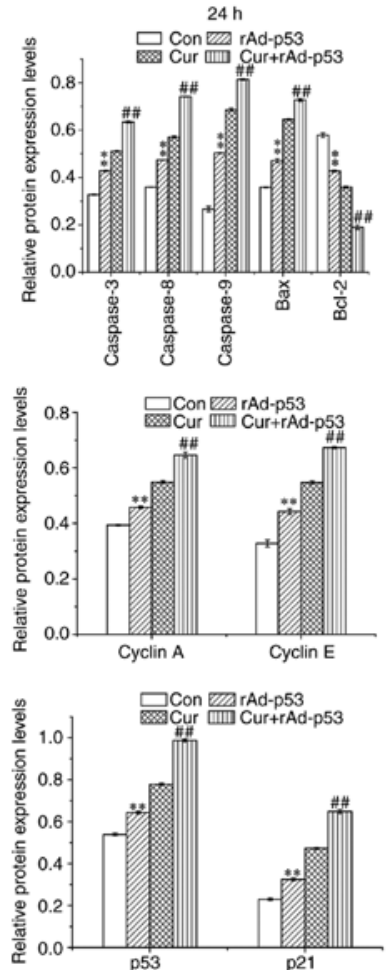

B

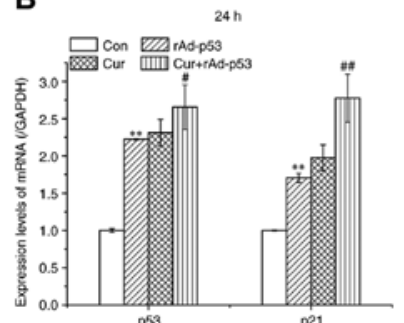

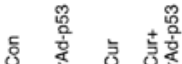

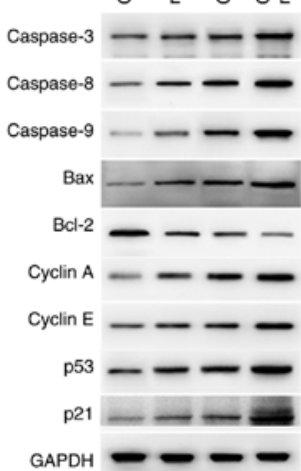

$48 \mathrm{~h}$
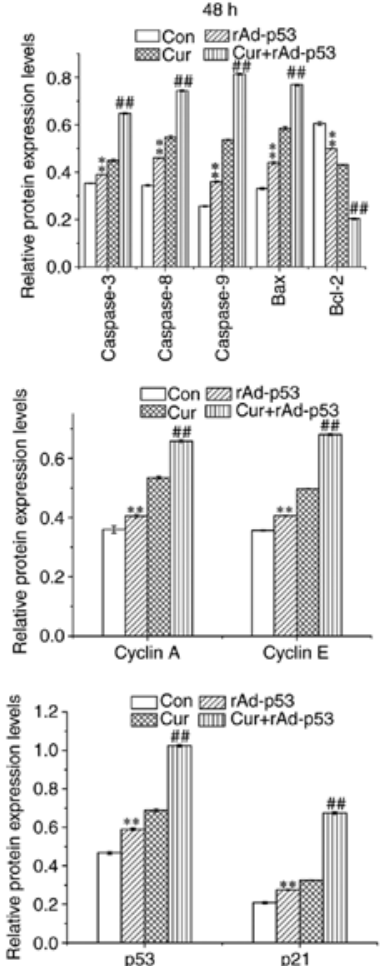

p53

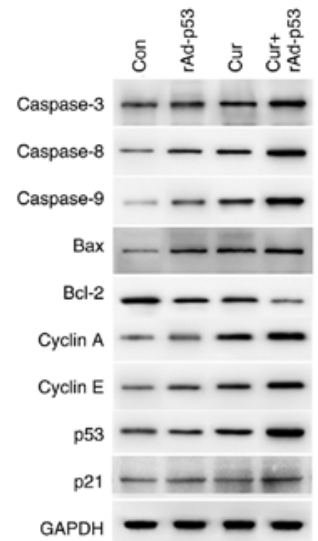

$72 \mathrm{~h}$
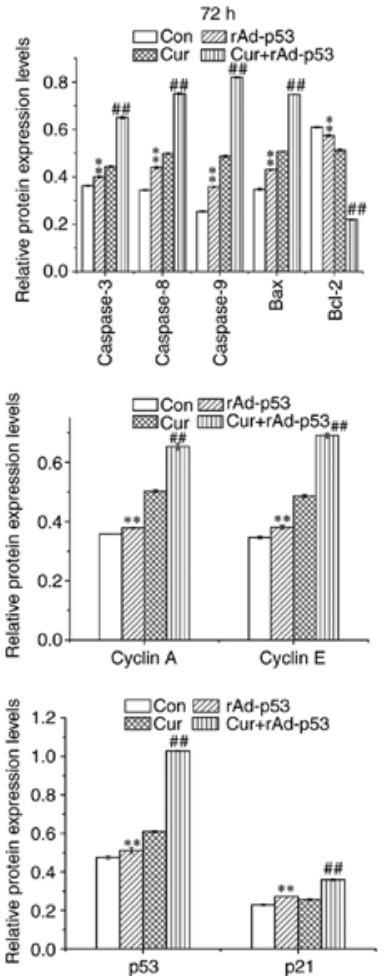

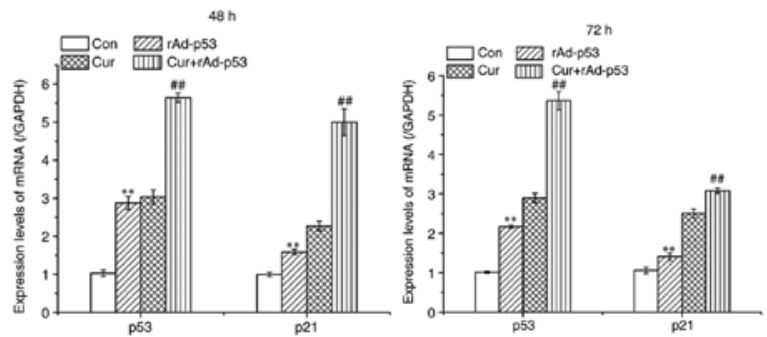

Figure 4. Effects of rAd-p53 and/or curcumin on the expression of proteins associated with apoptosis and cell cycle progression. (A) The proteins expression of Caspases 3, 8 and 9, and Bax, Bcl-2, cell cycle regulators Cyclins A and E, p53,p21 and (B) mRNA expression of p53 and p21 were measured following 24, 48 or $72 \mathrm{~h}$ rAd-p53 and/or curcumin treatment. Data are represented as mean \pm standard deviation $(\mathrm{n}=3)$. ${ }^{* *} \mathrm{P}<0.01$ vs. Con, ${ }^{\#} \mathrm{P}<0.05$ vs. Cur and ${ }^{\# \#} \mathrm{P}<0.01$ vs. Cur. Cur, curcumin; rAd-p53, recombinant human adenovirus-p53; Con, control

cells compared with non-treated cells. This observation is consistent with a previous report, where the intratumoral injection of rAd-p53 resulted in increased p53 expression in prostate cancer $(35,36)$. Downstream, the expression of the p53-targeted gene $C D K N 1$ followed a trend parallel to that of TP53, suggesting that the p53 protein produced following rAd-p53 treatment is physiologically active. The apoptosis rate was indicated to be markedly increased, as demonstrated by the upregulation of the pro-apoptotic proteins caspases 3, 8 and 9 in addition to Bax and coupled with the downregulation of the anti-apoptotic protein Bcl-2. EMT was also notably suppressed, as demonstrated by the downregulation of $\mathrm{N}$-cadherin, snail and twist expression, which are well documented markers of $\operatorname{EMT}(37,38)$. 

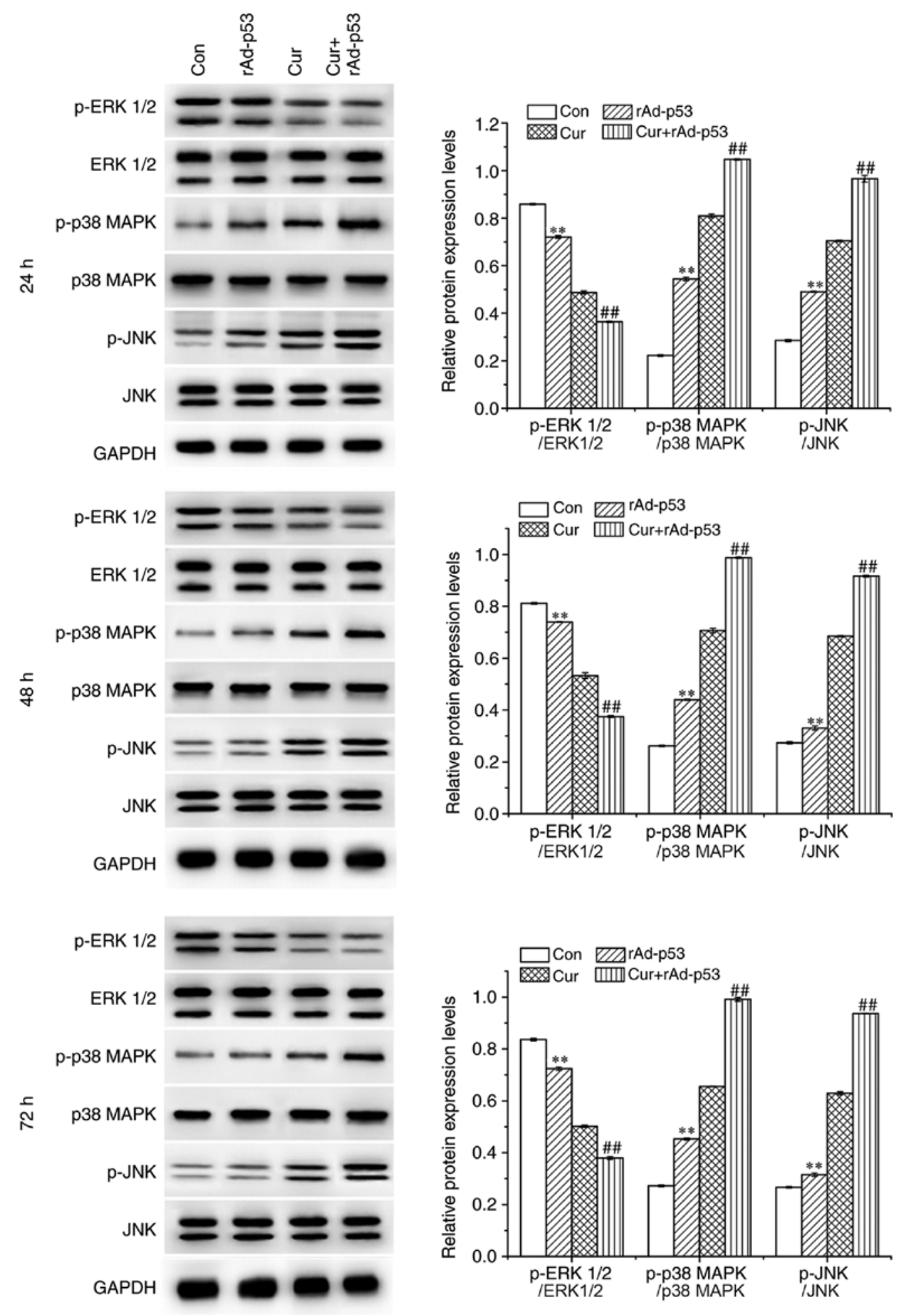

Figure 5. Effects of rAd-p53 and/or curcumin treatment on the activation of MAPK signaling pathways ERK, JNK and p38 MAPK in HepG2 cells after 24,48 or 72 h. Data are represented as mean \pm standard deviation $(n=3) .{ }^{* * *} \mathrm{P}<0.01$ vs. Con and ${ }^{\# \#} \mathrm{P}<0.01$ vs. Cur. Cur, curcumin; rAd-p53, recombinant human adenovirus-p53; Con, control.

TP53 often serves as a 'guardian of the genome', the deletion of which may result in the uncontrolled proliferation of tumor cells (39). The upregulation of TP53 expression that is induced by rAd-p53 treatment promoted human cervical cancer cell apoptosis through activation of the Bax gene and suppression of the Bcl-x gene and resulted in cell cycle arrest at the $G_{2} / M$ phase (40). The results of the present study are consistent with those observed in previous reports, which have demonstrated that TP53 activation is associated with liver cancer cell apoptosis by regulating the expression of Bcl-2 and caspases $(41,42)$, in addition to inhibiting cancer cell migration (43-45). TP53 activation has also been previously reported to serve an inhibitory role in the EMT process, in human oral mucosal fibroblasts and oral submucous 
fibrosis by downregulating $\mathrm{N}$-cadherin expression (46) and in colorectal cancer cells by downregulating Snail expression (37), which are findings consistent with the results of the present study.

Curcumin possesses anti-inflammatory and antioxidant properties and has also been observed to upregulate TP53 expression in tumor cells to exert several therapeutic effects $(47,48)$. Curcumin induces apoptosis and cell cycle arrest of cancer cells by targeting regulatory p53 (49). Previous in vivo and in vitro experiments have demonstrated that curcumin in combination with metformin induces apoptosis and suppresses the proliferation, invasion and metastasis of liver cancer cells by upregulating TP53 (50). In the present study, the combination of rAd-p53 and curcumin led to a higher expression of p53 compared with Cur treatment alone, synergistically promoting apoptosis, inhibiting cell proliferation and migration by regulating TP53. In addition, curcumin exerted anti-tumor effects by regulating the MAPK pathways. There are three subfamilies of MAPKs, including p38MAPK, JNKs and ERKs, all of which are related to apoptosis (51). A previous report has suggested that curcumin treatment induced retinoblastoma cell apoptosis by activating p38 MAPK and JNK (52). Similarly, curcumin-induced p38 MAPK activation resulted in FasL-associated apoptosis in human hepatocellular carcinoma Huh7 cells (53). Curcumin also induced apoptosis in HepG2 cells by activating the ROS-ASK1-JNK pathway (54). Consistent with previous studies, the co-treatment of rAd-p53 with curcumin in the present study resulted in the additive potentiation of p38MAPK and JNK activation, potentially resulting in apoptosis in this manner.

In conclusion, rAd-p53 and curcumin were applied individually or in combination to explore their influence on the liver cancer cell line HepG2. Compared with Cur treatment alone, the combined treatment synergistically promoted liver cancer apoptosis and inhibited cell migration. Mechanistically, these observed effects may be associated with TP53 expression and subsequent MAPK signaling. Overall, the present study provides new insights into possible targets for effective liver cancer therapy.

\section{Acknowledgements}

Not applicable.

\section{Funding}

No funding was received.

\section{Availability of data and materials}

The datasets used and/or analyzed during the current study are available from the corresponding author on reasonable request.

\section{Authors' contributions}

JQ and JY participated in the design of this work. JQ, WL, $\mathrm{MC}, \mathrm{WG}, \mathrm{CZ}$ and $\mathrm{BG}$ performed the experiments and analyzed data. JQ drafted the manuscript and JY revised the manuscript. All authors read and approved the final manuscript.

\section{Ethics approval and consent to participate}

Not applicable.

\section{Patient consent for publication}

Not applicable.

\section{Competing interests}

The authors declare that they have no competing interests.

\section{References}

1. Yu LX and Schwabe RF: The gut microbiome and liver cancer: Mechanisms and clinical translation. Nat Rev Gastroenterol Hepatol 14: 527-539, 2017

2. Jiang JF, Lao YC, Yuan BH, Yin J, Liu X, Chen L and Zhong JH: Treatment of hepatocellular carcinoma with portal vein tumor thrombus: Advances and challenges. Oncotarget 8: 33911-33921, 2017.

3. Bruix J, Han KH, Gores G, Llovet JM and Mazzaferro V: Liver cancer: Approaching a personalized care. J Hepatol 62: S144-S156, 2015

4. Poulain S, Roumier C, Bertrand E, Renneville A, Caillault-Venet A, Doye E, Geffroy S, Sebda S, Nibourel O, Nudel M, et al: TP53 mutation and its prognostic significance in Waldenstrom's macroglobulinemia. Clin Cancer Res 23: 6325-6335, 2017.

5. Friemel J, Rechsteiner M, Bawohl M, Frick L, Müllhaupt B, Lesurtel M and Weber A: Liver cancer with concomitant TP53 and CTNNB1 mutations: A case report. BMC Clin Pathol 16: 7, 2016.

6. Vogelstein B, Lane D and Levine AJ: Surfing the p53 network. Nature 408: 307-310, 2000

7. McCubrey JA, Lertpiriyapong K, Fitzgerald TL, Martelli AM, Cocco L,Rakus D, GizakA,Libra M,Cervello M,Montalto G, etal: Roles of TP53 in determining therapeutic sensitivity, growth, cellular senescence, invasion and metastasis. Adv Biol Regul 63: 32-48, 2017.

8. Soussi T and Wiman KG: TP53: An oncogene in disguise. Cell Death Differ 22: 1239-1249, 2015.

9. Kashofer K and Regauer S: Analysis of full coding sequence of the TP53 gene in invasive vulvar cancers: Implications for therapy. Gynecol Oncol 146: 314-318, 2017.

10. Li J, Pan J, Zhu X, Su Y, Bao L, Qiu S, Zou C, Cai Y, Wu J and Tham IW: Recombinant adenovirus-p53 (Gendicine) sensitizes a pancreatic carcinoma cell line to radiation. Chin J Cancer Res 25: 715-721, 2013.

11. Räty JK, Pikkarainen JT, Wirth T and Ylä-Herttuala S: Gene therapy: The first approved gene-based medicines, molecular mechanisms and clinical indications. Curr Mol Pharmacol 1: 13-23, 2008.

12. Li Y, Li B, Li CJ and Li LJ: Key points of basic theories and clinical practice in rAd-p53 (Gendicine ${ }^{\mathrm{TM}}$ ) gene therapy for solid malignant tumors. Expert Opin Biol Ther 15: 437-454, 2015.

13. Chen GX, Zheng LH, Liu SY and He XH: rAd-p53 enhances the sensitivity of human gastric cancer cells to chemotherapy. World J Gastroenterol 17: 4289-4297, 2011

14. Shen A, Liu S, Yu W, Deng H and Li Q: p53 gene therapy-based transarterial chemoembolization for unresectable hepatocellular carcinoma: A prospective cohort study. J Gastroenterol Hepatol 30: 1651-1656, 2015.

15. Li Y, Li LJ, Wang LJ, Zhang Z, Gao N, Liang CY, Huang YD and Han B: Selective intra-arterial infusion of rAd-p53 with chemotherapy for advanced oral cancer: A randomized clinical trial. BMC Med 12: 16, 2014.

16. Guan YS, Liu Y, Zou Q, He Q, La Z, Yang L and Hu Y: Adenovirus-mediated wild-type p53 gene transfer in combination with bronchial arterial infusion for treatment of advanced non-small-cell lung cancer, one year follow-up. J Zhejiang Univ Sci B 10: 331-340, 2009.

17. Buller RE, Runnebaum IB, Karlan BY, Horowitz JA, Shahin M, Buekers T, Petrauskas S, Kreienberg R, Slamon D and Pegram M: A phase I/II trial of $\mathrm{rAd} / \mathrm{p} 53$ ( $\mathrm{SCH} 58500$ ) gene replacement in recurrent ovarian cancer. Cancer Gene Ther 9: 553-566, 2002.

18. Staib F, Hussain SP, Hofseth LJ, Wang XW and Harris CC: TP53 and liver carcinogenesis. Hum Mutat 21: 201-216, 2003. 
19. Chin KY: The spice for joint inflammation: Anti-inflammatory role of curcumin in treating osteoarthritis. Drug Des Devel Ther 10: 3029-3042, 2016.

20. Lestari ML and Indrayanto G: Curcumin. Profiles Drug Subst Excip Relat Methodol 39: 113-204, 2014.

21. Darvesh AS, Aggarwal BB and Bishayee A: Curcumin and liver cancer: A review. Curr Pharm Biotechnol 13: 218-228, 2012.

22. El-Houseini ME, El-Agoza IA, Sakr MM and El-Malky GM: Novel protective role of curcumin and taurine combination against experimental hepatocarcinogenesis. Exp Ther Med 13: 29-36, 2017.

23. Marquardt JU, Gomez-Quiroz L, Arreguin Camacho LO, Pinna F, Lee YH, Kitade M, Domínguez MP, Castven D, Breuhahn K, Conner EA, et al: Curcumin effectively inhibits oncogenic NF- $\mathrm{KB}$ signaling and restrains stemness features in liver cancer. J Hepatol 63: 661-669, 2015.

24. Livak KJ and Schmittgen TD: Analysis of relative gene expression data using real-time quantitative PCR and the $2(-\Delta \Delta \mathrm{C}(\mathrm{T}))$ method. Methods 25: 402-408, 2001.

25. Hsia CC, Nakashima Y, Thorgeirsson SS, Harris CC, Minemura M, Momosaki S, Wang NJ and Tabor E: Correlation of immunohistochemical staining and mutations of p53 in human hepatocellular carcinoma. Oncol Rep 7: 353-356, 2000.

26. Honda K, Sbisà E, Tullo A, Papeo PA, Saccone C, Poole S, Pignatelli M, Mitry RR, Ding S, Isla A, et al: p53 mutation is a poor prognostic indicator for survival in patients with hepatocellular carcinoma undergoing surgical tumour ablation. Br J Cancer 77: 776-782, 1998.

27. Wu W, Liu S, Liang Y, Zhou Z, Bian W and Liu X: Stress hormone cortisol enhances Bcl2 like-12 expression to inhibit p53 in hepatocellular carcinoma cells. Dig Dis Sci 62: 3495-3500, 2017.

28. Li VD, Li KH and Li JT: TP53 mutations as potential prognostic markers for specific cancers: Analysis of data from The Cancer Genome Atlas and the International Agency for Research on Cancer TP53 Database. J Cancer Res Clin Oncol 145: 625-636, 2019.

29. Tu K, Zheng X, Zhou Z, Li C, Zhang J, Gao J, Yao Y and Liu Q: Recombinant human adenovirus-p53 injection induced apoptosis in hepatocellular carcinoma cell lines mediated by p53-Fbxw7 pathway, which controls c-Myc and cyclin E. PLoS One 8: e68574, 2013.

30. Chen SX, Xu WD, Yin GW, Xi W, Chen J, Xu QY and Ma GJ: Clinical therapeutic effect and biological monitoring of p53 gene in advanced hepatocellular carcinoma. Zhonghua Yi Xue Za Zhi 90: 2182-2186, 2010 (In Chinese).

31. Tian G, Liu J, Zhou JS and Chen W: Multiple hepatic arterial injections of recombinant adenovirus p53 and 5-fluorouracil after transcatheter arterial chemoembolization for unresectable hepatocellular carcinoma: A pilot phase II trial. Anticancer Drugs 20: 389-395, 2009.

32. Guan YS, Liu Y, He Q, Li X, Yang L, Hu Y and La Z: p53 gene therapy in combination with transcatheter arterial chemoembolization for HCC: One-year follow-up. World J Gastroenterol 17: 2143-2149, 2011

33. Yang ZX, Wang D, Wang G, Zhang QH, Liu JM, Peng P and Liu XH: Clinical study of recombinant adenovirus-p53 combined with fractionated stereotactic radiotherapy for hepatocellular carcinoma. J Cancer Res Clin Oncol 136: 625-630, 2010.

34. Cao W, Zhang JL, Feng DY, Liu XW, Li Y, Wang LF, Yao LB, Zhang $\mathrm{H}$ and Zhang J: The effect of adenovirus-conjugated NDRG2 on p53-mediated apoptosis of hepatocarcinoma cells through attenuation of nucleotide excision repair capacity. Biomaterials 35: 993-1003, 2014

35. Sasaki R, Shirakawa T, Zhang ZJ, Tamekane A, Matsumoto A, Sugimura K, Matsuo M, Kamidono S and Gotoh A: Additional gene therapy with Ad5CMV-p53 enhanced the efficacy of radiotherapy in human prostate cancer cells. Int J Radiat Oncol Biol Phys 51: 1336-1345, 2001.

36. Shirakawa T, Gotoh A, Gardner TA, Kao C, Zhang ZJ, Matsubara S, Wada Y, Hinata N, Fujisawa M, Hanioka K, et al: p53 adenoviral vector (Ad-CMV-p53) induced prostatic growth inhibition of primary cultures of human prostate and an experimental rat model. J Gene Med 2: 426-432, 2000.
37. Bai Z, Wang J, Wang T, Li Y, Zhao X, Wu G, Yang Y, Deng W and Zhang Z: The miR-495/Annexin A3/P53 axis inhibits the invasion and EMT of colorectal cancer cells. Cell Physiol Biochem 44: 1882-1895, 2017.

38. Angadi PV, Patil PV, Angadi V, Mane D, Shekar S, Hallikerimath S, Kale AD and Kardesai SG: Immunoexpression of epithelial mesenchymal transition proteins E-Cadherin, $\beta$-Catenin, and $\mathrm{N}-$ Cadherin in oral squamous cell carcinoma. Int J Surg Pathol 24: 696-703, 2016.

39. Curiel DT, Gerritsen WR and Krul MR: Progress in cancer gene therapy. Cancer Gene Ther 7: 1197-1199, 2000.

40. Liu YG, Zheng XL and Liu FM: The mechanism and inhibitory effect of recombinant human P53 adenovirus injection combined with paclitaxel on human cervical cancer cell HeLa. Eur Rev Med Pharmacol Sci 19: 1037-1042, 2015.

41. Liao W, Liu J, Liu B, Huang X, Yin Y, Cai D, Li M and Zhu R: JIB 04 induces cell apoptosis via activation of the $\mathrm{p} 53 / \mathrm{Bcl}$ 2/caspase pathway in MHCC97H and HepG2 cells. Oncol Rep 40: 3812-3820, 2018.

42. Cao Y, Cao J, Yu B, Wang S, Liu L, Tao L and Sun W: Berbamine induces SMMC-7721 cell apoptosis via upregulating p53, downregulating survivin expression and activating mitochondria signaling pathway. Exp Ther Med 15: 1894-1901, 2018.

43. Tamura M, Sasaki Y, Koyama R, Takeda K, Idogawa M and Tokino T: Forkhead transcription factor FOXF1 is a novel target gene of the p53 family and regulates cancer cell migration and invasiveness. Oncogene 33: 4837-4846, 2014.

44. Liu Y, Li L, Liu Y, Geng P, Li G, Yang Y and Song H: RECK inhibits cervical cancer cell migration and invasion by promoting p53 signaling pathway. J Cell Biochem 119: 3058-3066, 2018.

45. Zhang B, Yin X and Sui S: Resveratrol inhibited the progression of human hepatocellular carcinoma by inducing autophagy via regulating p53 and the phosphoinositide 3 kinase/protein kinase B pathway. Oncol Rep 40: 2758-2765, 2018.

46. Zheng L, Guan ZJ,Pan WT, Du TF, Zhai YJ and Guo J: Tanshinone suppresses arecoline-induced epithelial-mesenchymal transition in oral submucous fibrosis by epigenetically reactivating the p53 pathway. Oncol Res 26: 483-494, 2018.

47. Sidhar H and Giri RK: Induction of Bex genes by curcumin is associated with apoptosis and activation of p53 in N2a neuroblastoma cells. Sci Rep 7: 41420, 2017.

48. Li W, Wang Y, Song Y, Xu L, Zhao J and Fang B: A preliminary study of the effect of curcumin on the expression of p53 protein in a human multiple myeloma cell line. Oncol Lett 9: 1719-1724, 2015.

49. Kasi PD, Tamilselvam R, Skalicka-Woźniak K, Nabavi SF, Daglia M, Bishayee A, Pazoki-Toroudi H and Nabavi SM: Molecular targets of curcumin for cancer therapy: An updated review. Tumour Biol 37: 13017-13028, 2016.

50. Zhang HH, Zhang Y, Cheng YN, Gong FL, Cao ZQ, Yu LG and Guo XL: Metformin incombination with curcumin inhibits the growth, metastasis, and angiogenesis of hepatocellular carcinoma in vitro and in vivo. Mol Carcinog 57: 44-56, 2018

51. Wada T and Penninger JM: Mitogen-activated protein kinases in apoptosis regulation. Oncogene 23: 2838-2849, 2004.

52. Yu X, Zhong J, Yan L, Li J, Wang H, Wen Y and Zhao Y: Curcumin exerts antitumor effects in retinoblastoma cells by regulating the JNK and p38 MAPK pathways. Int J Mol Med 38: 861-868, 2016.

53. Wang WZ, Li L, Liu MY, Jin XB, Mao JW, Pu QH, Meng MJ, Chen XG and Zhu JY: Curcumin induces FasL-related apoptosis through p38 activation in human hepatocellular carcinoma Huh7 cells. Life Sci 92: 352-358, 2013.

54. Zheng R, You Z, Jia J, Lin S, Han S, Liu A, Long H and Wang S: Curcumin enhances the antitumor effect of ABT-737 via activation of the ROS-ASK1-JNK pathway in hepatocellular carcinoma cells. Mol Med Rep 13: 1570-1576, 2016.

This work is licensed under a Creative Commons Attribution-NonCommercial-NoDerivatives 4.0 International (CC BY-NC-ND 4.0) License. 